\title{
Ecological quality assessment of rivers and integrated catchment management in England and Wales
}

\author{
Paul LOGAN \\ Environment Agency, Rio House, Aztec West, Almondsbury, Bristol, United Kingdom \\ e-mail: paul.logan@environment-agency.gov.uk
}

\begin{abstract}
This paper deals with the ecological assessment of river quality and its relationship to integrated catchment management. The concept of catchment or river basin management has been a basic management tool in England and Wales since 1990; it is now being enshrined in the Water Framework Directive. Historically the statutory and operational drivers in the UK have lead to the development of distinctly different approaches to the management of water quality, water resources (quantity) and physical river structure. More recently a proactive approach to the sustainable use of water promulgated in the Local Environment Agency Plans has also dealt with the three management aspects in some isolation although greater effort has been made to present the issues in an integrated manner. The Water Framework Directive calls for further integration in river basin plans and associated programmes of measures. In the paper the three approaches are described and considered in light of the requirements of the Water Framework Directive. Water Quality classification and objective setting has been based on information from the survey of benthic macro-invertebrates. The Biological Monitoring Working Party Score and the predictive software River Invertebrate Prediction and Classification System (RIVPACS) have been used to set site-specific targets for management purposes. RIVPACS includes a reference database of minimally impacted sites for comparison with the observed data. This approach is in line with the requirements of the directive. Physical river structure work has been based on monitoring of in-river and river corridor characteristics. The River Habitat System (RHS) has also developed a reference database but is less well developed in terms of its predictive ability. The use of ecological information in Water Resource management has taken a different approach based on the concept of differential ecological sensitivity to the hydrological regime within the river. In order to develop a truly integrated approach to catchment management the importance of each the three aspects of management on the biological community will need to be prioritised. It will also be necessary to give careful consideration to the inter-actions between quality, quantity and structure.
\end{abstract}

Key words: ecological assessment, integrated catchment management, sustainable development, water framework directive

\section{INTRODUCTION}

This paper deals with the ecological assessment of river quality and its relationship to integrated catchment management. It is based on a brief presentation at a meeting on "Biological Monitoring" at the Istituto Italiano di Idrobiologia - Verbania Pallanza on $4^{\text {th }}$ September 2000. The approaches presented here are those currently being used or developed by the Environment Agency for England and Wales; as such this paper is not an attempt to review the current literature on the subjects considered, rather an exposition of the current application of ecological understanding within a major national regulatory organisation. As a consequence some of the documents referred to are internal to the Environment Agency and developmental in nature, however, this is in line with the raisons d'être of the meeting, at which the work was presented, which were mainly discursive.

Integrated catchment management or river basin management has been the most important concept supporting water management in England and Wales since the creation of the Regional Water Authorities in 1974. These authorities dealt with abstraction, discharges, land drainage, water supply, sewage disposal etc.- the complete management of the anthropogenic components of the water cycle. Some of this "integration" in a single authority was lost with the privatisation of the water industry in 1990 when the regulatory aspects were vested to a new authority the National Rivers Authority (NRA) and the provision of public water supply and disposal of sewage was taken over by water utility companies. However, the NRA maintained the concept of catchment management in their Catchment Management Plans (CMP) which were based on river basins. CMPs gave a description of the catchment, exposed the issues for the management of water in the catchment as viewed by the NRA and other stakeholders, and resulted in "Action Plans" to address the issues identified and agreed upon. With the creation of the Environment Agency in 1995 additional environmental duties relating to land and air where taken on and CMPs evolved into Local Environment Agency Plans (LEAPS) these took into account the new duties but where still based around catchment boundaries. The Agency still aims to regulate and manage the anthropogenic parts of the water cycle but with even greater involvement of stakeholders and further attempts to integrate regulation of water, land and air. The overall aim of the Agency is to contribute 
to sustainable development as a whole and specifically in the case of rivers to the sustainable use of water (Water Act 1996).

Sustainable development has been considered in terms of inter generation equity, "future generations will need a stock of assets no less than those of the current generation" - a review of these concepts in relation to river ecosystems is given by Gardiner \& Perala-Gardiner (2000). A standstill or status quo approach conflicts with most human nature, where parents usually desire to leave their children better off than themselves. It is with this more proactive stance that most ecological approaches to sustainable development are promulgated. The forthcoming European Water Framework Directive (WFD) (European Commission 2000) is an example of a proactive commitment; it includes the concept of "no deterioration" in ecological quality but the main aim is to generate plans for the gradual improvement of the ecological quality of all surface waters until they achieve "good" status. Within the WFD the aim to provide a more sustainable water system is based on the view that good ecological quality is more "natural" and therefore more sustainable. The definition of ecological status itself relates to the observed status of the site when compared with a reference status. The reference status is based on spatial, temporal or ecologically modelled conditions where human impacts are minimal. The assumption being that reference status is in itself sustainable because anthropogenic impacts are "minimal" or as maybe the case they are simply more sustainable than an impacted situation.

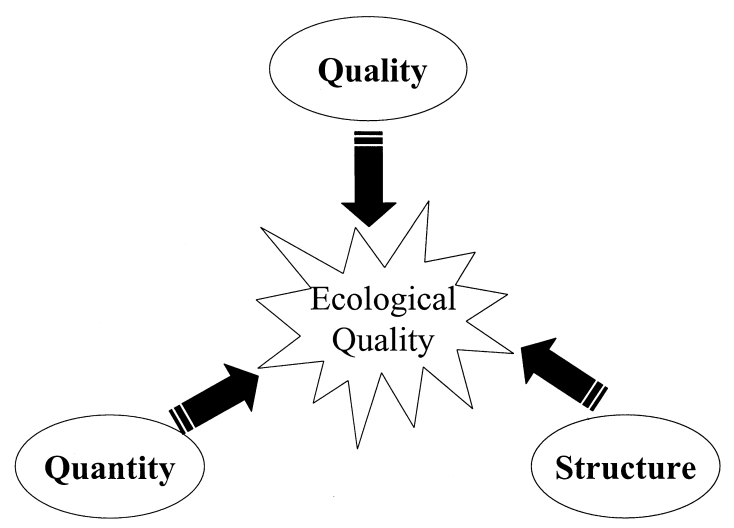

Fig. 1. The three components of management of ecological quality in rivers that are commonly used in the context of integrated catchment management.

The management of the environmental aspects of the water cycle, to achieve sustainability, as presented in the LEAPs, has been divided by the Agency into three main components of management: quality, quantity (resources) and physical structures (Fig. 1). Historically, in England and Wales, these three areas have associated with differing regulatory approaches and statutory in- struments. As a consequence the use of ecological information in the three management components has been quite different. The WFD has a more holistic view in combining the three approaches to achieve the single target of "good ecological quality". The three approaches used in England and Wales will be described and viewed in the context of their contribution to the requirements of the WFD and an integrated approach to catchment management.

\section{QUALITY}

Water quality management until recently has been based on the monitoring of chemical determinands (e.g. $\mathrm{pH}$, ammonia, suspended solids, biochemical oxygen demand); and sampling for chemical quality in England and Wales has been based on monthly spot sampling at sites throughout the country. Using this information two approaches to improvement of water quality have been devised. Firstly, a general classification approach has been used - the General Quality Assessment (GQA). In the GQA rivers lengths are classified into one of six categories $(\mathrm{A}-\mathrm{F})$ based on the levels of the measured determinands from: A - high quality with low levels chemical pollution, through to $\mathrm{F}$ - bad quality with high levels of pollutants. The management aim is based on reducing the river lengths in the lower classes and protecting those in the higher classes. Secondly objectives have been set in relation to the determinands measured by reference to their toxic effects in laboratory tests. In England and Wales several common determinands, aimed at controlling sewage pollution, have been combined to create such River Quality Objectives (RQO). Failure of any component determinand of the RQO is considered to be a failure of the whole objective. The UK government is now setting targets for the Agency in terms of a percentage reduction in RQO failures over coming years. For both approaches, improvement in river length classes and the reduction of RQO failures, positive results have been achieved in the past by increasing regulatory control of point source discharges. It is now becoming apparent that further improvements will require the control of more diffuse pollution sources (Fig. 2). Over the past twenty years complimentary systems of control have developed using the results of biological monitoring.

\subsection{Biological Monitoring Working Party}

It was recognised in the late 1960's and early 70's that biological information provided a more integrated measure of river quality than chemical monitoring, especially in terms of the polluting effects of mixtures of chemicals and the continuous monitoring that in situ flora and fauna provided. Following the chemical lead the first management initiative was to produce a classification system for assessing river lengths using results of biological monitoring. The Biological Monitoring Working Party (Biological Monitoring Working Party 


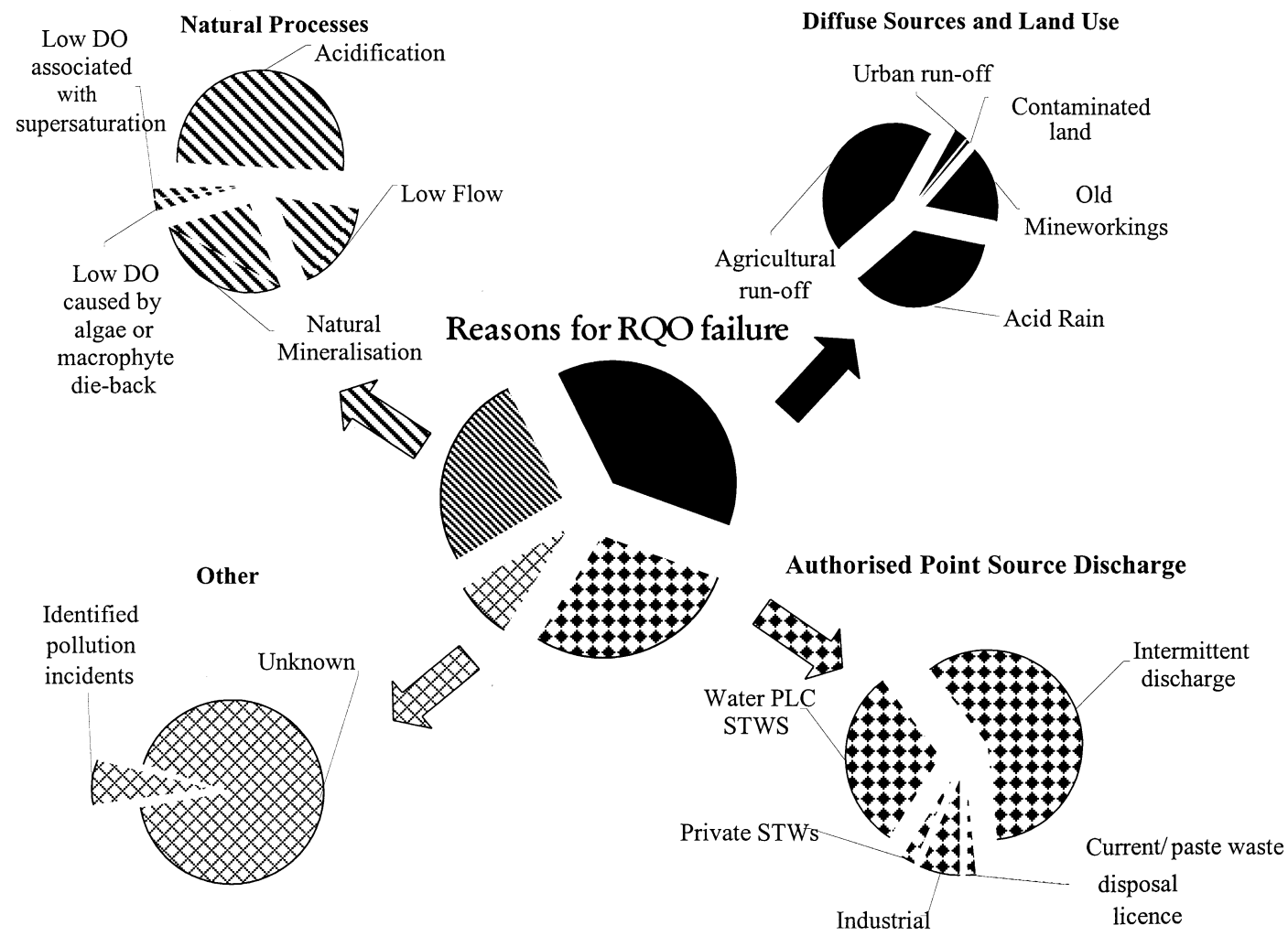

Fig. 2. An example of the use of River Quality Objectives and a presentation of possible reasons for failure.

1978) made the first attempt at developing a nationally applicable biological monitoring system for rivers using benthic macro-invertebrates. They developed a scoring system in which the sensitivity of different families of macro-invertebrates to riverine pollution was assessed and used to create an aggregate score for the site being sampled (the BMWP score). This scoring system has been used in one way or another in quinnqennial national surveys from 1980 until the current 2000 survey. The BMWP recommended that scores should only be compared on a temporal basis at sites to give the trend at the site and that spatial inter-site comparisons should not be made. This recommendation facilitated the comparison in river lengths over time for biological monitoring in a similar fashion to the chemical programme. Further they recommended the use of a derived measure - the Average Score Per Taxon (ASPT - the BMWP score divided by the number of taxa used in its calculation) as it was less prone to sampling errors.

The BMWP also identified that one of the major drawbacks with the system was that different unpolluted rivers gave rise to different BMWP scores due to naturally occurring variability in ecological communities. This made it impractical to compare the status of different types: for example lowland, slow-flowing silted rivers with upland, fast flowing mountain streams; this was a major drawback for a national system of classification.
In order to overcome this limitation a research project was proposed to develop a system whereby the differences between river types could be accounted for and lead to the development of the River Invertebrate Prediction and Classification System (RIVPACS). This system also allowed the development of Biological Quality Objectives (BQO) for rivers.

\subsection{River Invertebrate Prediction and Classification System (RIVPACS)}

A full account of the history and development of RIVPACS is given by Wright et al. (2000). A brief outline of the system is given below in order to discuss it in the context to the WFD and to compare it with the approaches to quantity and structural ecological assessment.

The essential building block of RIVPACS is a database of benthic macro-invertebrate samples taken from 614 "minimally" impacted river sites across the UK, which constitute the best examples of their type (in the opinion of the practising local aquatic biologists). This set of sites may be considered to be a spatial/temporal reference set in the context of the WFD. At each of the 614 sites samples were collected using at standardised kick and search technique (Murray-Bligh and Furse 1997) in three seasons of the year, spring summer and 
autumn. The macro-invertebrate data was used to classify the reference sites using two-way indicator species analysis (TWINSPAN) (Hill 1979), a divisive polythetic technique. The 614 reference sites were divided by the analysis into 35 classification groups, based on the faunal composition. Group size varied from 6 to 39 sites with a mean of 17.5 sites per group. These 35 groups relate to four major environmental/geographical divisions: groups 1-9 small streams throughout Great Britain, groups 10-17 upland streams and rivers, mainly in Scotland and N. England, groups 18-24 intermediate streams and rivers, mainly in N. England, Wales and S.W. England and groups 25-35 lowland stream and rivers, mainly in southern England.

At the same time as collecting the macro-invertebrates a large number of environmental variables were also measured, some were time invariant e.g. altitude, slope and some varied with the seasons e.g. discharge, substrate particle size. Chemical variables were represented as annual mean values. The classification groups defined on the biological criteria were then checked to see if they were coherent with respect to the measured environmental attributes. This was investigated using multiple discriminant analysis (MDA) (Klecka 1975). With this analysis it was possible using the environmental variables of a site to predict the probability of that site occurring in each of the original 35 classification groups. Using the probability of the site occurring in the classification groups and the percentage occurrence of the each of the taxa in those groups it, is also possible to predict the probability of capture of each of the taxonomic groups at the site. Thus it is now possible to predict, using a set of environmental variables, a "target" community that is indicative of "good" and "high" ecological quality by linking back to the "minimally" impacted reference site database.

As RIVPACS is able to predict a target community for the unimpacted condition - it is also possible to calculate the BMWP score for the target community. The observed score can then be compared with that predicted - the ratio of the two gives and estimate of the ecological impairment at a site. Similarly it is also possible to predict the total number of taxa that should be present and the ASPT. It is these ratios of observed to expected (or reference) that has been used to develop a Biological General Quality Assessment

\subsection{Biological General Quality Assessment and Biological Quality Objectives}

The outputs from RIVPACS have been used, in the first instance, to improve the classification of river lengths. A full description of the development of the Biological General Quality Assessment (BGQA) is give by Hemsley-Flint (2000). The rivers are classified into one of six categories (Tab. 1) based on the ratios of observed to predicted values for ASPT and total number of taxa. As the classification is based on a site-specific tar- get spatial comparisons between different river types are facilitated. Further the system has allowed the statistical measurement of precision and accuracy in terms of classification and in particular a way of estimating statistically significant changes in class.

The concept of a "target" community has also allowed the consideration of setting BQOs. The development of BQOs are still at an early stage, but it is likely that the target of "good ecological status", required by the WFD, will be fulfilled for riverine invertebrates by using the RIVPACS approach. The specific requirement of the WFD to express the status in terms of a ratio of observed to reference is integral to that already taken in BGQA using both RIVPACS and BMWP score. A database of environmental stresses has been collated and this will be used to correlate BQO failures with a particular stress or set of stresses, in similar fashion to that shown for chemistry in figure 2 (Murray-Bligh, pers. comm.). It should be noted that the biological approach relates the $\mathrm{BQO}$ failures to integrated environmental effects whilst the complimentary chemical approach relates back to the original toxicity based objectives.

\section{QUANTITY}

Ecological assessment in relation to water resource management in England and Wales has dealt mostly with site or scheme specific initiatives and the inclusion of ecological information has take quite a different route from that used for quality management. Much of the work relating hydrology and ecology has been recently reviewed by Gore (1996) and Stalnaker (1994). In England and Wales individual abstraction licences and other water resource schemes (e.g. reservoirs, impoundment and water transfers) have dealt with the ecological component on a cases by case basis (Petts 1996). Recent work, within the Agency, by Extence et al. (1999), has produced a more general approach linking macro-invertebrate communities to hydrological regimes using a scoring system (Lotic-invertebrate Index for Flow Evaluation - LIFE).

As yet none of these methods have been taken up as a national approach for England and Wales, and indeed over the past 20 years a wide variety of local methodologies have evolved in different parts of the country. However, the Environment Agency is now required by the UK government to produce abstraction management strategies for all hydrological catchments (river basins) in England and Wales (Department of the Environment Transport and the Regions 1999). This requires not only a consistent approach to water resource estimation, but also a national approach to the estimation of the "environmental needs" for water within the catchments. This "environmental need" includes that required to protect aquatic flora and fauna and thus an ecological assessment is now urgently required. Previously a variety of research and development projects have been undertaken to develop a nationally acceptable approach; the 
Tab. 1. Definition of six Biological General Quality Assessment grades, used by the Environment Agency for England and Wales.

\begin{tabular}{ll}
\hline Grade & Definition \\
\hline a) Very Good & The biology is similar to (or better than) that expected for an average and \\
unpolluted river of this size, type and location. There is a high diversity of \\
families, usually with several species in each. It is rare to find a dominance of \\
any one family. \\
The biology shows minor differences from Grade A and falls a little short of \\
that expected for an unpolluted river of this size type and location. There may \\
be a small reduction in the number of families that are sensitive to pollution, \\
and a moderate increase in the number of individual creatures in the families \\
that tolerate pollution (like worms and midges). This may indicate the first \\
signs of organic pollution. \\
c) Fairly Good & $\begin{array}{l}\text { The biology is worse than expected for an unpolluted river of this size, type } \\
\text { and location. Many of the sensitive families are absent or the number of } \\
\text { individual creatures is reduced, and in many cases there is a marked rise in the } \\
\text { number of the individual creatures in the families that tolerate pollution. } \\
\text { The biology shows big differences from that expected for an unpolluted river } \\
\text { of this size, type and location. Sensitive families are scarce and contain only } \\
\text { small numbers of individual creatures. There may be a range of those families } \\
\text { that tolerate pollution and some of these may have high numbers of individual } \\
\text { animals. } \\
\text { The biology is restricted to animals that tolerate pollution, with some families } \\
\text { dominant in terms of the numbers of individual creatures. Sensitive families } \\
\text { will be rare or absent. } \\
\text { The biology is limited to a small number of very tolerant families, often only } \\
\text { worms, midge larvae, leeches and the water hoglouse. These may be present } \\
\text { in very high numbers. Even these may be missing if the pollution is toxic. In } \\
\text { the very worst case there may be no life present in the river. }\end{array}$ \\
e) Poor & \\
f) Bad &
\end{tabular}

most promising being the Surface Water Abstraction Licence Procedure (SWALP) (National Rivers Authority 1995). This method is based on the estimation of ecological sensitivities for rivers and the relation of these to the control measures for flow and abstraction licensing within catchments.

\section{1. Surface Water Abstraction Licence Procedure (SWALP)}

An important component of SWALP is the concept of the naturalised flow within the catchment. Models are used to calculate the total water resource within the catchment assuming no anthropogenic influences, further the models also indicate the distribution of the flow through the year based on monthly mean figures. In terms of the WFD this "naturalised" flow could be considered the reference situation for the catchment water resource and hydrological regime. The models also include some consideration of the interaction between groundwater and surface waters.

Within SWALP the determination of "environmental need" - constituting the absolute flow requirement for the flora and fauna, is not yet possible for whole communities of flora and fauna. Some progress has been made using physical habitat simulation models (Stalnaker 1994) in relating flow and useable habitat area for specific target species. However, SWALP takes a different approach, which is based on an estimation of the relative sensitivity of different rivers and their associated flora and fauna to changes in the hydrological regime. The method does not indicate specific flow requirements for each river's environmental need, rather it pragmatically provides higher levels of protection to those rivers that are estimated as most sensitive.

Three components of ecological sensitivity are scored within the system; physical river structure, ecology (based on macro-invertebrates and macrophytes), and fisheries. For each component 16 different sensitivity classes are estimated by expert opinion ranging from extremely flow sensitive to highly flow insensitive. For example in the fisheries component salmonid spawning areas are classified as highly sensitive whilst poor coarse fisheries are classified as flow insensitive. The expert estimates are based on the current ecological state of the catchment, which may be "impacted", rather than the potential state or "good ecological quality" although some allowance is made for improvements likely to occur in the short term (less than 5 years). The use of current status does not fit well with the aspiration of "good ecological" quality in the WFD. Once the classes of the three components have been estimated an overall class is calculate by summing the sensitivity 

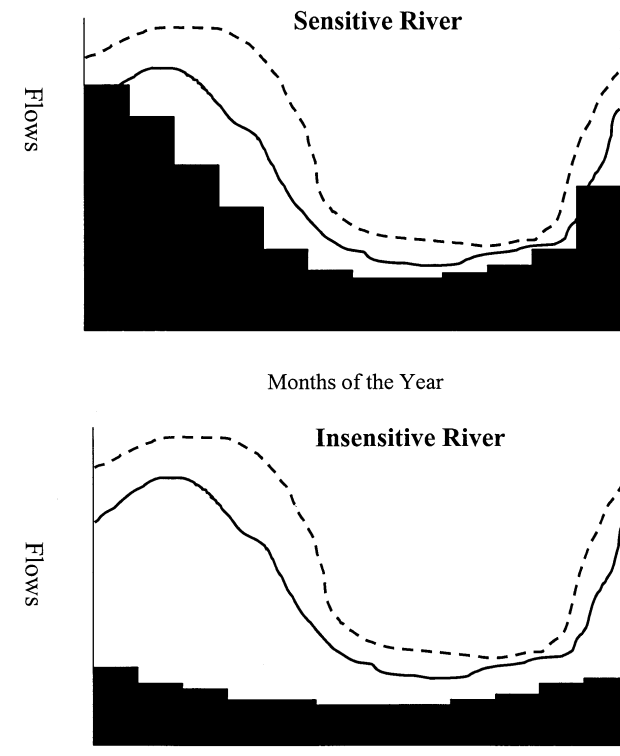

Months of the Year
Key

Naturalised flow

Actual flow

"Hands off" flow

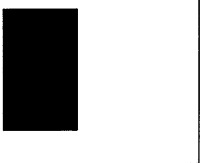

Fig. 3. Simplified surface Water Abstraction Licensing Practice - showing the differing "Hands Off" Flows for Ecologically Sensitive and Insensitive Rivers. classes of the three separate components. A possible problem with this summing is that a highly sensitive component may be downgraded by lower classes in the other two components.

The overall class is related to a series of flow management regimes. The important aspects of these management regimes are: (i) the concept of the "hands off flow" (HOF) and (ii) differential "take" for rivers of different sensitivities. HOFs are those flows below which abstraction from the river must cease: differential protection of sensitive and insensitive rivers is given by setting higher HOF for sensitive rivers when compared with insensitive rivers where the HOF may constitute only a small part of the "naturalised" flow. Differential "take" is achieved by differentiating between rivers of differing sensitivities with respect to the percentage of water over and above the HOF that can be abstracted: lower percentage take is allowed for sensitive rivers when compared with insensitive rivers. River flows may fall below the HOF in natural droughts - but these low flows should not be exacerbated by abstraction (Fig. 3).

\subsection{Development of SWALP}

A recent Agency assessment of the SWALP methodology has recommended several modifications which should improve the objectivity of the method, bringing it more into line with the requirements of the WFD and ensuring an approach consistent with water quality methods. Most important is the use of RIVPACS (Wright 2000) to predict macro-invertebrate communities and from this provide predicted LIFE scores (Extence et al. 1999) which can then be compared with observed LIFE scores; with all the associated advantages that have been given in the Quality section of this paper. It has been suggested that a database of reference macrophyte information should also be collected and again predictive software developed. Macrophytes are import in flow management as they not only respond to flow changes but they also create changes in flow conditions by their growth within the channel. This would facilitate the estimation of "good ecological quality" for at least two of the ecological attributes required by the WFD. These predictive models would allow the methodology a greater degree of objectivity and move away from sensitivities based on current "impacted" sites. Further recommendations relate to the combining of components - rather than summing sensitivities the most sensitive component could be used to judge the overall sensitivity - based on the precautionary principle and again supporting the drive towards "good ecological quality" or preserving a "high ecological quality" status.

\section{STRUCTURE}

The relationship between ecology and river habitat structure has been developed in a third way, different again from the quality and quantity approaches. Initial work in this area was based on a local operational need to give advice, particularly to flood defence engineers, about the ecological consequences of channel alteration activities. Within England and Wales this lead to the development of a standardised method of survey - the River Corridor Survey (RCS) (National Rivers Authority 1992). The RCS approach was essentially a map based system and not conducive to a national system of classification of the physical structure of rivers. It was seen as important that such a national system should assist in setting targets for habitat quality for 
river managers to work towards. The system should also be able to measure the impact (both negative and positive) of river channel management. This need lead to the development of the River Habitat Survey (RHS) (Raven et al. 1998).

\subsection{River Habitat Survey}

RHS is a system for assessing the character and quality of rivers based on their physical structure. It has four distinct components: (i) a standard method for field survey, (ii) a computer database for entering results from survey sites and comparing them with other sites, (iii) a suite of methods for assessing habitat quality, and (iv) a method for describing the extent of artificial channel.

Data collection is based on a standard $500 \mathrm{~m}$ length of river. Information is collated on a four-page inventory of physical site features. During the field survey features of the channel and adjacent river corridor are recorded. Map based information is also collated including: altitude, slope, geology, distance from source etc.

An early requirement of the system was to establish a geographically representative baseline sample of river habitat features. This was achieved by surveying a network of reference sites based on a stratified random sample of those rivers classified for water quality purposes. However, the RHS reference sites were selected independently of existing chemical and biological sampling points, because the latter are not located in a random manner. The RHS baseline represents habitat features and impacts associated with rivers and streams throughout the UK it includes pristine, semi-natural and severely modified sites (note the inclusion of impacted sites means that these reference sites would not be "reference sites" in the context of the WFD).

During the first survey year (1994) it became clear that very few of the reference sites had a combination of totally unmodified channel and extensive associated semi-natural landscape. It was decided in order to establish a "top quality" series of benchmark sites, additional sites would have to be surveyed. Sites were selected by a panel of experts based on existing information indicating their high conservation status in terms of their plant or animal communities. It was difficult to find $500 \mathrm{~m}$ lengths in lowland England and Wales which were benchmark in the strictest sense, such is the extent of human influence. Some benchmarks therefore fall someway short of "natural" but they nevertheless represent the best in the context of the high level of structural degradation throughout the UK. These benchmark sites could be considered a "reference" set in the context of WFD.

Using the database generated by the RHS an estimate of habitat quality has been developed. The system is based on four precepts: (i) evaluation is determined at the site level; (ii) quality is based on the presence of channel and river corridor features which are known to be of value to wildlife; (iii) the two main factors which determine habitat quality are the diversity and "naturalness" of the physical structure and (iv) the system is calibrated, wherever possible using known top quality sites surveyed specifically for this purpose (benchmark sites). The assumption is that "in general, habitat and biological diversity in rivers are closely linked" (Raven et al. 1998), and the features "known" to be of value to wildlife are based on the judgement of a panel of experts. Models are now being developed using the RHS habitat features to predict fish communities, with some success (Naura, pers. comm.). Similar approaches have already been developed by Milner et al. (1998) in developing HABSCORE, which relates salmonid populations to habitat resources. This type of work will add credence to the assumption that high habitat diversity leads to high ecological quality.

During the initial development of RHS attempts were made to devise a single, fixed national classification of river types to allow comparisons between rivers of the same physical type in order to assess habitat quality in the context of other similar rivers. However, the eleven types proposed proved to be unworkable and now a nearest neighbour technique is used to give meaningful comparisons to judge whether a site is outstanding or important in terms of its physical habitat diversity and "naturalness" (Raven et al. 1998). Those of highest quality could again be considered a group of "reference" sites in the context of the WFD.

It has also been possible using RHS to estimate the degree of anthropogenic modification the river has undergone. The Habitat Modification Score (HMS) of the site is based on the number of anthropogenic modifications that are present in the river channel. Low scoring sites are considered to be pristine or semi-natural whilst a site with a high HMS is considered to be heavily modified or even severely modified. This type of scoring may be of value in considering the designation of "heavily modified" sites in the WFD and again "pristine" sites could be considered part of a reference set for the hydromorphological attributes required by the WFD.

\section{CONCLUSIONS}

The ecological assessment of the management triangle of water quality, quantity and structure has given rise to three quite different approaches in England and Wales. These different approaches relate to the differing needs of the current regulatory and statutory frameworks. The approaches are also at quite different stages of evolution and sophistication. The quality methods have been developed over the longest period, are the most objective having the most developed statistical backup (Clarke 2000). The structural components also have a well-developed conceptual framework. In contrast the quantity approach has taken quite a different tack, with the emphasis on measuring relative ecological 
sensitivities rather than absolute ecological targets. Each approach has been created in some isolation from the others and although they is some cross referencing in each of the systems little effort has gone into consideration of the inter-action of the elements and the consequent ecological outcomes (Fig. 4).

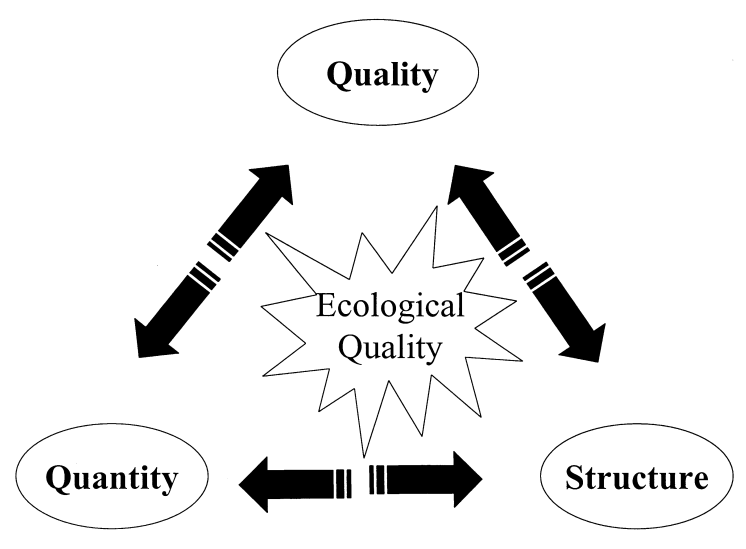

Fig. 4. Interactions between the three management components of ecological quality commonly used in integrated catchment management planning.

The WFD provides the most important statutory driver to bring the approaches together in a unified river basin management plan. Monitoring of the flora and fauna gives the opportunity to measure an integrated response to the management of the three components, especially if this monitoring is to be in relation to a commonly derived and agreed "target" floral and faunal community. Both quality and structure elements have significant reference databases already collated and are well on the way to providing some of the major requirements of the WFD. However, the quantity approach in currently based on the concept of relative sensitivities rather than an absolute target. This concept would be more closely linked to WFD requirements if the sensitivity analysis were to be based on a target community of representing "good ecological status" rather than the status quo.

When the observed biological community is not of good ecological quality it will be necessary to investigate the reasons for the disparity in order to develop a action plan and programme of measures of to address the issues and progress toward "good ecological status". As a consequence diagnostic tools will be required to identify the most significant stresses with respect to the ecology. These diagnostic tools will also need to take into account the inter-action between the three components of quality, quantity and structure.

\section{ACKNOWLEDGMENTS}

The author would like to thank Prof. O. Ravera and Dr A. Davies for the opportunity to contribute to the meeting and to all colleagues at the Istituto Italiano di
Idrobiologia for their wonderful hospitality. The opinions expressed are the authors and not those of the Environment Agency.

\section{REFERENCES}

Biological Monitoring Working Party. 1978. Final report: assessment and presentation of the quality of rivers in Great Britain. Unpublished report, Department of the Environment, Water Date Unit.

Clarke, R.E. 2000. Uncertainty in estimates of biological quality based on RIVPACS. In: J.F. Wright, D.W. Sutcliffe \& M.T. Furse (Eds), Assessing the biological quality of freshwaters, RIVPACS and other techniques. Freshwater Biological Association, Ambleside, UK: 373 pp.

Department of the Environment Transport and the Regions. 1999. Taking Water Responsibly. Department of the Environment Transport and the Regions, London.

European Commission. 2000. Directive of the European Parliament and of the Council 2000/60/EC establishing a framework for community action in the field of water policy. European Commission PE-CONS 3639/1/00 REV 1, Luxemborg.

Extence, C.A., D.M. Balbi \& R.P. Chadd. 1999. River flow indexing using British benthic macro-invertebrates: a framwork for setting hydroecological objectives. Environment Agency, Bristol, UK.

Gardiner, J.L. \& N.C. Perala-Gardiner. 2000. Conservation, ecosystem use and sustainability. In: P.J. Boon, B.R. Davies \& G.E. Petts (Eds), Global perspectives on river conservation: science, policy, and practice. Wiley, Chichester: $548 \mathrm{pp}$.

Gore, J.A. 1996. Responses of Aquatic Biota to Hydrological Change. In: G. Petts \& P. Calow (Eds), River Biota, Diversity and Dynamics. Blackwells Oxford: $257 \mathrm{pp}$.

Hemsley-Flint, B. 2000. Classification of the biological quality of rivers in England and Wales. In: J.F. Wright, D.W. Sutcliffe \& M.T. Furse (Eds), Assessing the biological quality of freshwaters, RIVPACS and other techniques. Freshwater Biological Association, Ambleside, UK: 373 pp.

Milner, N.J., R.J. Wyatt, \& K. Broad. 1998. HABSCORE applications and future developments of related habitat methods. Aquatic Conservation. Marine and Freshwater Ecosystems, 8: 633-644.

Murray-Bligh, J.A.D. \& M.T. Furse. 1997. Procedure for collecting and analysing macro-invertebrate samples for RIVPACS. Environment Agency, Bristol.

National Rivers Authority. 1992. River Corridor Surveys, Method and Procedures. NRA, Bristol, UK.

National Rivers Authority. 1995. Surface Water Abstraction Licensing Policy Development. Project Report 505, NRA, Bristol UK.

Petts, G.E. 1996. Water allocation to protect river ecosystems. Regulated rivers, research and management. Vol. 12: 353365.

Raven P.J., N.T. Holmes, F.H. Dawson, P.J.A. Fox, M. Everard, I. Fozzard \& K.J. Rouen. 1998. River Habitat Quality, the physical character of rivers and streams in the UK and Isle of Man. Environment Agency, Bristol, UK: 85 pp.

Stalnaker, C.B. 1994. Evolution of instream flow habitat modelling. In: Calow, P. \& G.E. Petts (Eds). The Rivers Handbook. 2. Blackwell Scientific Publications, Oxford: 276286.

Water Act. 1996. HMSO, London.

Wright, J.F., D.W. Sutcliffe \& M.T. Furse (Eds). 2000. Assessing the biological quality of freshwaters, RIVPACS and other techniques. Freshwater Biological Association, Ambleside, UK: 373 pp. 